\title{
EVALUATION OF THE AXIAL STRESSES OF A GAS PIPELINE MADE OF REINFORCED POLYETHYLENE PIPES UNDER CONDITIONS OF PERMAFROST SOILS
}

\author{
Yu. Yu. Fedorov, S. N. Popov, A. V. Savvina*, S. V. Vasilyev, A. K. Rodionov \\ Institute of Oil and Gas Problems, Siberian Branch of the Russian academy of Sciences, \\ 1 Oktyabrskaya St., Yakutsk, 677980, Russian Federation \\ *Corresponding author. E-mail: io1982@mail.ru; \\ address for correspondence: 677000, Yakutsk, ul. Chernyshevskogo, 16/1-68. \\ Tel.: 89247614641
}

Monitoring of gas pipelines provides data necessary to justify the minimum value of the safety factor. Stresses in a gas pipeline made of reinforced polyethylene pipes with local soil heaving are evaluated with the use of a three-point diagram of loading by a concentrated force of a beam with a thin annular section. It is obvious from the calculations that the magnitude of axial stresses under the influence of soil heaving is far from critical. The safety factor is twice as high as the normative value.

Keywords: polyethylene pipes, underground gas pipeline, frozen soil, low temperatures, stress-strain state.

DOI: $10.17804 / 2410-9908.2017 .3 .036-041$

\section{References}

1. Wessing W., Grass K., Kanet J., Capdevielle J-P. Novel PE Gas Supply System for a Maximum Operating Pressure of 16 bar. In: Proc. Int. Gas Res.Conf., Vancouver, Canada, 2004.

2. Ameln D., Wessing W. Aramid-Reinforced Plastic Pipes. High-Strenght Pipes for Gas Transportation. In: Proc. Int. Gas Res. Conf., Vancouver, Canada, 2004.

3. Wolters Mannes, Wessing Werner, Dalmolen Bert, Eckert Robert, Wuest Juergen Reinforced Thermoplastic Pipeline (RTP) Systems for Gas Distribution. In: Proc. 23rd World Gas.Conf., Amsterdam, 2006.

4. Shalyapin S.V., Gvozdev I.V., Simonov-Emelyanov I.D. Calculation and prediction of the strength of reinforced multilayer polymer pipes. Vestnik MITKhT, 2012, vol. 7, no. 4, pp. 112-116. (In Russian).

5. Pepelyaev V.S., Tarakanov A.I. Reinforced polyethylene pipes for gas pipelines with operating pressure exceeding 1.2 MPa. Polimergaz, 2006, no. 4, pp. 14-18. (In Russian).

6. Gorilovsky M.I., Gvozdev I.V., Shvabauer V.V. On the strength analysis of reinforced polymer pipes. Polimernye truby, 2005, no. 2, pp. 22-25. (In Russian).

7. Fattakhov M.M., Teregulov R.K., Shammazov I.A., Mastobaev B.N., Movsun-zade E.M. Transport uglevodorodnogo syria po truboprovodam iz polimernykh i kompozitnykh materialov [Transportation of Hydrocarbon Raw Materials through Pipelines Made of Polymer and Composite Materials]. S.-Pb., Nedra Publ., 2011, 288 p. (In Russian).

8. Gustov D.S. Economic justification for the construction of gas pipelines made of composite materials. Territoriya "Neftegaz", 2016, no. 3, pp. 154-159. (In Russian).

9. Struchkov A.S., Fedorov Yu.Yu. Deformability of polyethylene PE80 pipes at low temperatures. Plasticheskie massy, 2002, no. 2, pp. 43-46. (In Russian).

10. Fedorov Yu.Yu., Savvina A.V. The stress-strain state of underground gas pipelines under permafrost conditions. Neftegazovoe Delo, 2008, no. 1. Available at: http://ogbus.ru/authors/Fyodorov/Fyodorov_1.pdf (accessed 15.06.2017). (In Russian).

11. Struchkov A.S., Ivanov V.I., Fedorov S.P., Poselskaya A.V. Positive and negative factors of the interaction of a polyethylene gas pipeline with soil in the North. In: Trudy III Evraziyskogo sim- 
poziuma po problemam prochnosti materialov $i$ mashin dlya regionov holodnogo klimata, ch. 3 [Transactions of the $3^{\text {rd }}$ Eurasian Symposium on the Strength of Materials and Machines To be Operated in Cold Climate Regions, Part 3]. Yakutsk, 2006, pp. 163-167. (In Russian).

12. Danzanova E.V., Poselskaya A.V., Struchkov A.S., Sivtsev E.Ya. Results of pilot industrial testing of an underground polyethylene gas pipeline. In: Problemy i perspektivy kompleksnogo osvoeniya mestorozhdeniy poleznykh iskopaemykh kriolitozony: materialy mezhdunarodnoy konferentsii [Problems and Prospects of the Complex Development of Natural Resources in the Cryolithozone]. Yakutsk, 2005, pp. 144-148. (In Russian).

13. Babenko F.I., Fedorov S.P., Fedorov Yu.Yu., Levin A.I., Ivanov V.I., Poselskaya A.V. Studying the physical and mechanical properties of reinforced polyethylene pipes in cold climates. Fundamentalnye Problemy Sovremennogo Materialovedeniya, 2007, vol. 4, no. 2, pp. 10-14. (In Russian). 
Подана в журнал: 29.06 .2017

УДК 678.067.5:539.4

DOI: $10.17804 / 2410-9908.2017 .3 .036-041$

\title{
ОЦЕНКА ОСЕВЫХ НАПРЯЖЕНИЙ ГАЗОПРОВОДА ИЗ АРМИРОВАННЫХ ПОЛИЭТИЛЕНОВЫХ ТРУБ В УСЛОВИЯХ МНОГОЛЕТНЕМЕРЗЛЫХ ГРУНТОВ
}

\author{
Ю. Ю. Федоров, С. Н. Попов, А. В. Саввина*, С. В. Васильев, А. К. Родионов \\ ФГБУН Институт проблем нефти и газа СО РАН, \\ ул. Октябрьская, д. 1, г. Якутск, Республика Саха (Якутия), Российская Федераџия \\ *Ответственный автор. Электронная почта: io1982@ mail.ru; \\ адрес для переписки: 677000, г. Якутск, ул. Чернышевского, д. 16/1-68. \\ Телефон: 8-924-761-46-41
}

Организация мониторинга действующих участков газопроводов позволяет получить необходимые данные для обоснования минимального значения коэффициента запаса прочности. Оценка напряжений в газопроводе из армированных полиэтиленовых труб при локальном пучении грунта проводится с использованием трехточечной схемы нагружения сосредоточенной силой балки тонкого кольцевого сечения. Из проведенных вычислений следует, что величина осевых напряжений при воздействии фактора пучения грунта далека от критической, коэффициент запаса прочности выше нормативного значения в 2 раза.

Ключевые слова: полиэтиленовые трубы, подземный газопровод, мерзлый грунт, низкие температуры, напряженно-деформированное состояние.

\section{1. Введение}

Применением полиэтиленовых армированных синтетическими нитями труб в системах газораспределения высокого давления серьезно занимаются в Германии, Испании и Франции [1-3]. Исследовательская практика в области использования армированных полиэтиленовых труб на давление до 1,2 МПа в России в основе своей базируется на опыте научных исследований и экспериментального строительства применительно к условиям умеренного климата [4-7]. Опытно-промышленные работы, проведенные в Западной Сибири и технико-экономические расчеты показывают, что широкое внедрение армированных полиэтиленовых труб для межпоселковых газопроводов позволит сократить затраты на монтаж, ускорить строительство и существенно снизить эксплуатационные расходы [8].

Подземный газопровод в период эксплуатации, кроме внутреннего давления подвергается дополнительному воздействию нагрузок, что особенно значимо для условий прокладки в зоне многолетнемерзлых грунтов. Эти и другие внешние факторы учитываются коэффициентом запаса прочности при расчете допустимого рабочего давления в газопроводе на заданный срок эксплуатации, порядка 50 лет. При мониторинге осуществляется контроль процессов, протекающих в элементах конструкции объекта и окружающем грунте в целях раннего обнаружения негативного изменения их напряженно-деформированного состояния, которое может привести к переходу объекта в аварийное состояние.

В статье использованы результаты мониторинга опытно-промышленного участка подземного межпоселкового газопровода «Тулагино-Капитоновка-Кангалассы», изготовленного из армированных полиэтиленовых труб со средним адгезионным слоем. Строительство участка осуществлено согласно требованиям СНиП 42-01-2002 «Газораспределительные сети» (актуализированная редакция), глубина заложения труб 1,5 м., длина участка 275 м. 
Вертикальные перемещения трубопровода, возникающие при воздействии пучения и просадки грунта, определяются относительно специально установленного репера. Результаты измерений вертикальных перемещений газопровода относительно реперной точки приведены на рис. 1. Промораживание грунта начинается с верхних слоев, нижние слои остаются еще при положительных температурах, в результате чего происходит перемещение газопровода вниз. В дальнейшем перемещения трубы имеют колебательный характер. Максимальное погружение трубы в грунт наблюдается в марте, затем труба начинает подъем, достигающий максимума в первой половине лета. По результатам измерений можно отметить некоторую зависимость амплитуды перемещений от амплитуды годовых колебаний температуры воздуха и стенки газопровода.

Сравнение данных по перемещениям между контрольными точками показывает примерную картину поведения подземного газопровода. Существуют небольшие различия между значениями замеров, так как по трассе опытно-промышленного участка грунт характеризуется различными уровнями влажности и рельефа.

Замеры перемещений зимы 2008-2009 гг. подземного газопровода относительно ранее проведенных измерений, показывают значительное отличие. Максимальное зафиксированное перемещение составило примерно 40 мм. Такие перемещения объясняются повышением уровня влажности грунта и погодными условиями зимы периода 2008-2009 гг.: длительно низкие температуры окружающего воздуха и малая толщина снежного покрова (15-20 см).

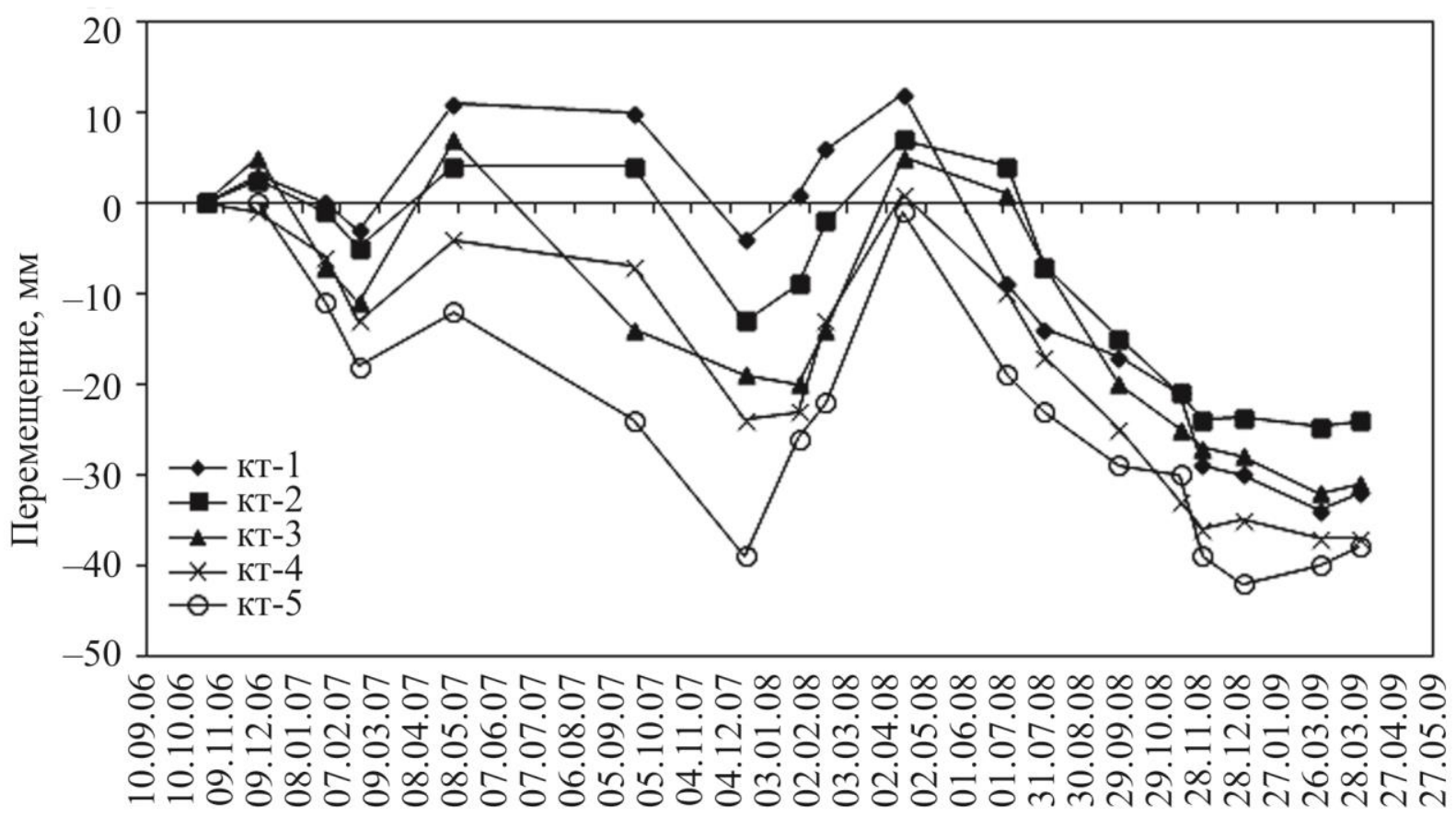

Рис. 1. Значения вертикальных перемещений подземного газопровода на опытно-промышленном участке объекта «МПГ Тулагино-Капитоновка-Кангалассы»

\section{2. Постановка задачи и методы решения}

Оценка напряжений в газопроводе при локальном пучении грунта проводится с использованием трехточечной схемы нагружения сосредоточенной силой балки тонкого кольцевого сечения (рис. 2). Внутреннее давление 1,2 МПа на показатели прочности осевого растяжения существенного влияния не оказывает [9]. 


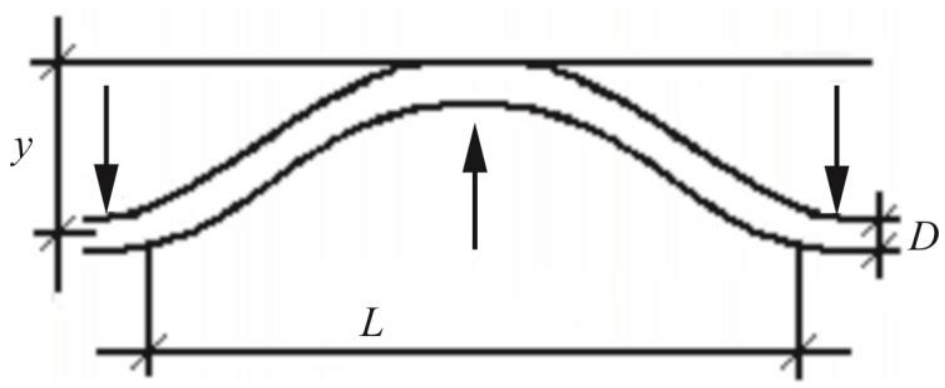

Рис. 2. Трехточечная схема нагружения сосредоточенной силой балки тонкого кольцевого сечения

Общее напряжение $\left(\sigma_{\text {об}}\right)$ в осевом направлении запишем в виде суммы напряжений: температурного $\left(\sigma_{\text {темп }}\right)$; изгиба от неравномерного пучения грунта $\left(\sigma_{\text {изг }}\right)$; напряжения, возникающего в результате осевого растяжения при подъеме участка трубы в условиях жесткого защемления остальной части газопровода мерзлым грунтом $\left(\sigma_{\text {раст }}\right)[10]:$

$$
\sigma_{\text {об }}=\sigma_{\text {темп }}+\sigma_{\text {изг }}+\sigma_{\text {раст }}
$$

т. е. в конечном виде:

$$
\sigma_{\text {об }}=\varepsilon_{\mathrm{T}} \cdot E(T)+6 y E(T) \frac{D}{(L)^{2}}+2,66 \cdot E(T) \cdot\left(\frac{y}{L}\right)^{2},
$$

где $\varepsilon_{\mathrm{T}}$ - температурная деформация материала трубы; $L$ - длина участка газопровода, подвергнутого изгибу неравномерным пучением, м; $y$ - величина вертикального перемещения газопровода, оценивается как $y=\theta_{\text {об }}\left(1-H_{0} / \gamma_{\text {кр }}\right)$, где $H_{0}$ - глубина заложения трубопровода, м; $\theta_{\text {об }}$ - общее пучение, замеряемое экспериментально, м; $\gamma_{\text {кр }}$ глубина промерзания, м. Феноменологическую формулу в условиях многолетнемерзлых грунтов следует применять при ограничениях: $H_{0}<<\gamma_{\text {кр }} ; \theta_{\text {об }}=y$.

\section{3. Результаты и обсуждение}

По данным многофакторного анализа деформируемости полиэтиленовых труб при низких температурах [9] получены расчеты по величине предельного радиуса изгиба полиэтиленовой трубы ПЭ80 и номограмма низкотемпературных деформаций частей труб. Используя экспериментальные данные пучения грунтов, рассчитано осевое напряжение газопровода.

Таблица - Результаты расчетной оценки осевых напряжений газопровода

\begin{tabular}{|c|c|c|c|c|c|c|c|c|c|c|c|}
\hline \multicolumn{7}{|c|}{ Исходные данные } & \multicolumn{5}{c|}{ Результаты } \\
\hline$H_{0}, \mathrm{м}$ & $T,{ }^{\circ} \mathrm{C}$ & $L, \mathrm{м}$ & $y, \mathrm{м}$ & $\varepsilon_{\mathrm{T}}, \%$ & $\begin{array}{c}E, \\
\mathrm{MПа}\end{array}$ & $\begin{array}{c}\sigma_{\text {пред, }} \\
\text { МПа }\end{array}$ & $\begin{array}{c}\sigma_{\text {темп, }} \\
\text { МПа }\end{array}$ & $\begin{array}{c}\sigma_{\text {изг }}, \\
\text { МПа }\end{array}$ & $\begin{array}{c}\sigma_{\text {раст }}, \\
\text { МПа }\end{array}$ & $\begin{array}{c}\sigma_{\text {общ, }} \\
\text { МПа }\end{array}$ & $\mathrm{C}$ \\
\hline 1,5 & -8 & 6 & 0,04 & 0,18 & 1450 & 28 & 2,61 & 1,35 & 0,17 & 4,13 & 6,78 \\
\hline
\end{tabular}

$\mathrm{C}=\sigma_{\text {пред}} / \sigma_{\text {общ }}-$ коэффициент запаса прочности.

Из таблицы следует, что величина осевых напряжений при воздействии фактора пучения грунта далека от критической, коэффициент запаса прочности выше нормативного значения в 2 раза.

Таким образом, поведение уложенного в грунт опытного участка газопровода за период наблюдения характеризуется закономерными ожидаемыми перемещениями, величина которых соизмерима с ранее зафиксированными на аналогичных сооружениях на территории $\operatorname{PC}(Я)[11,12]$. 


\section{4. Заключение}

На глубине заложения газопровода температура стенки трубы не опускается ниже температуры вязко-хрупкого перехода для труб из полиэтилена марки ПЭ100 $\left(-10 \div-15{ }^{\circ} \mathrm{C}\right)$ и распространение быстрых трещин исключается. Таким образом, на основании результатов мониторинга, проведенного на газопроводе, следует, что для труб с внутренним и внешним слоем из ПЭ100, у которых в диапазоне температур от минус $15{ }^{\circ} \mathrm{C}$ до минус $20{ }^{\circ} \mathrm{C}$ разрушения происходят вязко, глубина заложения может быть существенно уменьшена. При этом величина заглубления должна определяться результатами геокриологических изысканий из условия превышения температурой грунта температуры вязко-хрупкого перехода минус $5 \div 0{ }^{\circ} \mathrm{C}$ для труб из ПЭ80 и минус $15 \div$ минус $20^{\circ} \mathrm{C}$ для ПЭ100, определенным по результатам ранее проведенных исследований [13].

\section{Литература}

1. Novel PE Gas Supply System for a Maximum Operating Pressure of 16 bar / Wessing W., Grass K., Kanet J., Capdevielle J-P. // Int. Gas Res. Conf., Vancouver, Canada : proceedings. 2004.

2. Ameln D., Wessing W. Aramid-Reinforced Plastic Pipes. High-Strenght Pipes for Gas Transportation // Int. Gas Res. Conf., Vancouver, Canada : proceedings. - 2004.

3. Reinforced Thermoplastic Pipeline (RTP) Systems for Gas Distribution / Mannes Wolters, Werner Wessing, Bert Dalmolen, Robert Eckert, Juergen Wuest // $23^{\text {rd }}$ World Gas. Conf., Amsterdam : proceedings, 2006.

4. Шаляпин С. В., Гвоздев И. В., Симонов-Емельянов И. Д. Расчет и прогнозирование прочности многослойных полимерных армированных труб // Вестник МИТХТ. - 2012. - Т. 7 , № 4. - С. 112-116.

5. Пепеляев В. С., Тараканов А. И. Полиэтиленовые армированные трубы для газопроводов с рабочим давлением свыше 1,2МПа // Полимергаз. - 2006. - № 4. - С. 14-18.

6. Гориловский М. И., Гвоздев И. В., Швабауэр В. В. К вопросу прочностного расчета армированных полимерных труб // Полимерные трубы. - 2005. - № 2. - С. 22-25.

7. Транспорт углеводородного сырья по трубопроводам из полимерных и композитных материалов / М. М. Фаттахов, Р. К. Терегулов, И. А. Шаммазов, Б. Н. Мастобаев, Э. М. Мовсун-заде / СПб. : Недра, 2011. - 288 с.

8. Густов Д. С. Экономическое обоснование сооружения газопроводов из композиционных материалов // Территория «НЕФТЕГАЗ». - 2016. - № 3. - С. 154-159.

9. Стручков А. С., Федоров Ю. Ю. Деформируемость полиэтиленовых труб из ПЭ80 при низких температурах // Пластические массы. - 2002. - № 2. - С. 43-46.

10. Федоров Ю. Ю., Саввина А. В. Напряженно-деформированное состояние подземных газопроводов в условиях многолетней мерзлоты [Электронный ресурс] // Нефтегазовое дело. - 2008. - № 1. - URL: http://ogbus.ru/authors/Fyodorov/Fyodorov_1.pdf (дата обращения: 15.06.2017). 11. Позитивные и негативные факторы взаимодействия полиэтиленового газопровода с грунтами в условиях Севера / А. С. Стручков, В. И. Иванов, С. П. Федоров, А. В. Посельская // Труды III Евразийского симпозиума по проблемам прочности материалов и машин для регионов холодного климата : сборник материалов. Часть 3. - Якутск, 2006. - С. 163-167. 12. Результаты опытно-промышленных испытаний подземного полиэтиленового газопровода / Е. В. Данзанова, А. В. Посельская, А. С. Стручков, Е. Я. Сивцев // Проблемы и перспективы комплексного освоения месторождений полезных ископаемых криолитозоны: материалы международной конференции. - Якутск, 2005. - С. 144-148.

13. Исследование физико-механических свойств армированных полиэтиленовх труб в условиях холодного климата / Ф. И. Бабенко, С. П. Федоров, Ю. Ю. Федоров, А. И. Левин, В. И. Иванов, А. В. Посельская // Фундаментальные проблемы современного материаловедения. -2007 . - Т. 4, № 2. - С. 10-14. 